\title{
EFEITO DA BANDAGEM ELÁSTICA FUNCIONAL NO EQUILÍBRIO DINÂMICO: ESTUDO PILOTO
}

\author{
Shirley Ferreira Campos ${ }^{1}$ \\ Mário Vinicius de Andrade Vitório ${ }^{2}$ \\ João Pedro Palma de Castro ${ }^{3}$ \\ Bruno Prianti ${ }^{4}$ \\ Rodrigo Silva e Santos ${ }^{5}$
}

Resumo: A Bandagem elástica funcional consiste em uma técnica que pode auxiliar na melhora da integração sensorial do corpo com o ambiente, proporcionando aumento da propriocepção local e consequente melhora no equilíbrio postural estático e dinâmico. Objetivo: Observar os efeitos da aplicação da bandagem elástica no equilíbrio dinâmico por meio do Y balance test (YBT). Métodos: Foi realizado um estudo de caso com um sujeito do sexo feminino que foi submetido a três condições experimentais; bandagem elástica com tensão (B/CT), sem bandagem (SB) e bandagem elástica sem tensão (B/ST). Resultados: Aponta melhora no equilíbrio dinâmico para o teste realizado com (B/ST) nas direções anterior e póstero-medial, já a (B/CT) se mostra superior somente a nenhuma intervenção (SB). Conclusão: $A$ partir deste estudo observou-se que a bandagem elástica apresentou melhora significativa no equilíbrio dinâmico, porém mais estudos são necessários para comprovar sua eficácia.

Palavras-chave: Equilíbrio postural; Instabilidade articular; Bandagem funcional elástica.

\footnotetext{
${ }^{1}$ Fisioterapia/Universidade Paulista-UNIP, Brasil. E-mail: shirleycampos30@hotmail.com.

2 Fisioterapia/Universidade Paulista-UNIP, Brasil. E-mail: mariovitorio@outlook.com.

${ }^{3}$ Fisioterapia/Universidade Paulista-UNIP, Brasil. E-mail: joaopedro95@gmail.com.

4 Docente do curso pós-graduação/Universidade do vale do paraíba-UNIVAP, Brasil. E-mail: brunoprianti@hotmail.com.

${ }^{5}$ Docente do curso de Fisioterapia da Universidade Paulista-UNIP, Brasil. E-mail: rodrigo.santos@unitau.com.br.
} 